\title{
Emotional and Behavioral Difficulties and Academic Achievement in Immigrant Adolescents in Special Education
}

\author{
Cécile Rousseau $^{1,2, *}$, Sally Mustafa ${ }^{2} \&$ Caroline Beauregard $^{2,3}$ \\ ${ }^{1}$ Division of Social and Transcultural Psychiatry, McGill University, Montreal, Canada \\ ${ }^{2}$ Transcultural Research and Intervention Team (Erit), CSSS de la Montagne, Montreal, Canada \\ ${ }^{3}$ Department of Educational Psychology and Adult Education, Université de Montréal, Montreal, Canada \\ *Correspondence: Division of Social and Transcultural Psychiatry, McGill University, Montreal, Quebec, H3N 1Y9, \\ Canada. Tel: 1-514-273-3800, ext. 6452. E-mail: cecile.rousseau@mcgill.ca
}

Received: April 21, 2015

Accepted: June 16, 2015 Online Published: September 9, 2015

doi:10.5430/wje.v5n5p21

URL: http://dx.doi.org/10.5430/wje.v5n5p21

\begin{abstract}
The literature emphasizes that the school environment is a key factor for the mental health and academic achievement of immigrant and refugee children. However, few studies examined the role of school environment and peer relationships for these youth attending a special education class. The aim of this paper is to study the association between emotional difficulties and academic performance and their correlates in first and second generation immigrants assigned to a special class in a multiethnic environment. The results emphasize the need to adopt an eco-systemic model to understand the complex and probably bidirectional relations between the mental health symptoms and academic performance in immigrant adolescents identified as having difficulties by the school system. The salience of peer relations and classroom environment suggests that schools need to promote positive school-based relationships to improve immigrant adolescent mental health.
\end{abstract}

Keywords: immigrant; refugee; youth; mental health; special education

\section{Introduction}

Studies of North American and European populations have long highlighted the overlap (from 25 to $75 \%$ depending on the study) that exists between learning problems and emotional and behavioral problems-a phenomenon often described in terms of comorbidity (Bauer, Keefe, \& Shea, 2001; Benner, Nelson, \& Epstein, 2002; Lambros, Ward, Bocian, MacMillan, \& Gresham, 1998; Rock, Fessler, \& Church, 1997; Maurizi, Grogan-Kaylor, Granillo, \& Delva, 2013a). Because of the co-occurrence of emotional and behavioral difficulties with learning difficulties, and because both represent a challenge for teachers, children and youth with such problems are often assigned to special education settings. However, despite the association between emotional and behavioral difficulties, which is influenced by ethnicity and gender, this association is not unidirectionally related to learning problems and may reflect complex interactions between the environment and children's and youth learning trajectories (Rothon et al., 2009).

Socio-economic deprivation is associated with learning, emotional and behavioral difficulties in minority youth as it is in the rest of the population (Coutinho, Oswald, Best, \& Forness, 2002). Added to this are specific factors for recently arrived refugee and immigrant children and youth, such as premigratory exposure to trauma and migration-related losses that must be taken into account as they may significantly influence school adjustment and academic trajectory (Barowsky \& McIntyre, 2010). In the field of ethnic studies, the ethnic and racial biases underlying referral to special classes have been studied extensively in the United States over the last 20 or 30 years. Yet, this does not mean that minority children and youth are systematically overrepresented in special education. In 2003-2004 in Quebec (Canada), the proportion of immigrant students classified as "handicapped or with adaptation or learning problems" was comparable to the proportion for all students (Ministère de l'Éducation, 2006).

Nevertheless, studies have also highlighted the adverse effects of segregation from peers for minority group children having weak academic performance, who are over-represented in disadvantaged schools (Glick \& White, 2003; Rumbaut \& Portes, 2001; Van Hook \& Stamper Balistreri, 2002). Research has suggested that these children, often newly arrived in the country, may experience a double exclusion that could sever their feeling of belonging to their new 
society. This feeling may be due to the perceptions their families and communities have of being assigned to a special class and to the social position attached to minority cultural status in socioeconomically disadvantaged neighborhoods (Bibeau, Chan-Yip, Lock, Rousseau, \& Sterlin, 1992; Rousseau, Drapeau, \& Corin, 1996; Kanouté, Vatz Laaroussi, Rachédi, \& Tchimou Doffouchi, 2008). For immigrant and refugee children, the school environment appears to be an important factor in the process of belonging or exclusion and on how students engage in school. In fact, Suarez-Orozco (2009) identified the key role of positive school-based relationships in the academic engagement of immigrant youth. More precisely, Maurizi and collaborators (2013b) emphasized the significance of teacher and peer support as predictors of school belonging. Furthermore, another study with 894 children and adolescents showed that social relationships moderate the relation between depressive symptoms and academic achievement, underscoring the importance that mental health can play in the promotion of academic success (Maurizi et al., 2013a). These studies, which did not look at youth who were already designated by schools as having difficulties, invite us to rethink the role of school environment and peer relationships for immigrant and refugee youth attending special education classes in particular.

In this paper, we examine the relationship between emotional and academic difficulties and sociodemographic, family and environmental correlates in first- and second-generation immigrant students assigned to special classes in a multiethnic environment. Because of the special class setting, we hypothesize that socio-environmental correlates, (peer relationships and classroom environment) may buffer the possible stigma associated with this specific environment.

\section{Methods}

\subsection{Participants}

Four hundred and sixty four secondary school students attending high density multiethnic schools (five) and having been put in special classes (twenty nine) due to learning or behavioral problems constituted the population of this study.

These classes were comprised of youth (12 to 17 years of age) with academic delays of at least two years. One third of the classes were composed of youth not having finished their elementary school curriculum. A second third was composed of seventh graders, and the final third of eighth graders (with a few ninth graders).

The five high schools participating in this study were located in the greater Montreal area. They were selected because they serve disadvantaged, highly multiethnic communities.

On the island of Montreal, there are a total of 27 public francophone high schools designated to receive newly arrived immigrants. Our sample corresponded to $20 \%$ of these and to around $50 \%$ of high schools in highly multiethnic neighborhoods. The participating schools were located in different parts of the Montreal island. Three of them were among the poorest on the island while the other two had mixed population profiles, in that they had children from middle-class families in their gifted programs but also served extremely poor neighborhoods. Overall, these schools were highly representative of Montreal's multiethnic high schools. Twenty-nine homeroom teachers agreed to have their classes participate in the study.

All students assigned to special classes based on behavioral and learning problems in grades 7-10 were invited to participate in the study. At the start of the school year, schools distributed study participation consent forms to parents and assent forms to students. The overall participation rate was $80 \%$. Although we did not record information about those who refused to participate, reports from research assistants suggested that there may have been an over-representation of oppositional youth, thus implying a potential bias for the sample.

Data were collected through self-report questionnaires filled out during a 75-minute class period. They were designed so that students with learning difficulties could complete them in approximately 45 minutes. Teachers also filled out a questionnaire about their students.

The following socio-demographic variables were documented: socioeconomic status (family income and parents' employment status), country of birth of youth and of parents, ethnicity, migratory history, years in Canada, and language proficiency (English and French). In addition, contact with or use of mental health services outside of school was noted. 


\subsection{Instruments}

\subsubsection{Strengths and Difficulties Questionnaire (SDQ).}

Emotional and behavioral symptoms and associated impairment were measured by two informants using the SDQ; the adolescents themselves and one of their main teachers. This was in accordance with three main principles: (1) complementarity between teacher and student perspectives (multiple informants); (2) maximizing the transcultural validity of the instruments; (3) opting for instruments with robust psychometric properties, given the heterogeneity of the sample.

The SDQ is a 25 -item Likert scale assessing emotional and behavioral symptoms. It includes an impairment measure that examines symptoms in terms of chronicity, distress, social impairment, and burden for others. The SDQ has been translated into more than 20 languages and has been widely used in culturally diverse settings (Goodman, 2001). A choice of the French or English version was offered to the adolescents, and a version in their native tongue was available on request. The psychometric properties of the SDQ in diverse cultural communities are good (Goodman et al., 2008).

Emotional and behavioral symptoms were assessed by the SDQ global score (teacher and youth reports).

Impairment associated with emotional and behavioral symptoms was assessed by the Impact Supplement of the SDQ completed by the adolescents and their teachers.

A cutoff score of 16 (or 1 for the Impact Supplement) is the requirement for identifying clinical caseness for SDQ total symptoms or impairment, respectively.

\subsubsection{Adolescent Friendship Inventory (AFI)}

Relationships with peers were assessed using the AFI, a scale designed by Rubenstein et al. (1989). This 30-item instrument requires adolescents to indicate to what degree, on a scale of 1 to 5 , the feelings expressed by statements correspond to their personal feelings about their networks of peers. It has been shown to have good psychometric properties in transcultural settings (Rousseau, Drapeau, \& Rahimi, 2003).

\subsubsection{What Is Happening in this Class? (WIHIC)}

The WIHIC questionnaire, developed by Aldridge and Fraser (2002), is a measure that assesses the classroom environment to evaluate student cohesiveness, teacher support, involvement, task orientation, cooperation and equity in the class group. It is composed of a total score of 23 questions, and has also been used in culturally diverse settings.

\subsubsection{School performance}

School performance was assessed on the basis of the first report cards of the school year, issued in November, as data collection took place in December. Students' grades in Mathematics and French, the two compulsory subjects in special classes, were recorded.

\subsection{Statistical Analysis}

Data were analyzed using SPSS Version 17 software (SPSS Inc., Chicago, Il, US). Descriptive statistics were used to summarize students' baseline characteristics. Means, standard deviations and frequencies were calculated for all study variables. Pearson correlations were used to calculate the associations among continuous study variables. Independent sample $t$-tests were used to detect differences in SDQ total scores by dichotomous demographic study variables.

The impact of study variables on the emotional and behavioral symptoms of the youth when measured by themselves or teachers was examined with linear regression analysis. The variables used in the models included the sociodemographic variables of age, gender, having a father or mother caregiver, and family economic status, in addition to having witnessed violence or persecution in the country of origin, and French and mathematics grades, as independent variables. These correlates were selected because of their significance in the literature, and were entered in the model if their bivariate association with at least one of the outcome variables (self or teacher SDQ) was significant $(\mathrm{p}<0.05)$.

All statistical tests were two-sided, and a $P$-value equal to or less than 0.05 was considered significant.

\section{Results}

Our sample consisted of 464 youth enrolled in special classes for students with learning and/or behavioral problems. The mean age of the students was approximately 14 years (Table 1 ). 
Table 1. Demographic Characteristics

\begin{tabular}{|c|c|c|}
\hline Variable & & N $(\%)$ or Mean (SD) \\
\hline \multirow[t]{2}{*}{ Sex } & Boys & $262(56.5 \%)$ \\
\hline & Girls & $202(43.5 \%)$ \\
\hline Age (years) & & $13.84(1.24)$ \\
\hline Household members & & $4.54(1.61)$ \\
\hline \multirow[t]{4}{*}{ Migration history } & First generation & $198(42.7)$ \\
\hline & Second generation & $216(46.6)$ \\
\hline & Mixed couple & $28(6.0)$ \\
\hline & Canadian origin & $20(4.3)$ \\
\hline \multirow[t]{3}{*}{ Self identity } & Canadian & $31(6.7)$ \\
\hline & Other & $230(49.6)$ \\
\hline & Do not know & $97(20.9)$ \\
\hline \multirow[t]{5}{*}{ Reason for immigration } & Economic & $53(11.4)$ \\
\hline & Politic & $39(8.4)$ \\
\hline & Discrimination & $14(3.0)$ \\
\hline & Other (mostly education) & $30(6.5)$ \\
\hline & Do not know & $153(33.0)$ \\
\hline \multirow[t]{3}{*}{ Violence/persecution } & Witnessed violence in country of origin & $37(8)$ \\
\hline & Was persecuted in country of origin & $48(10.3)$ \\
\hline & Either & $62(13.4)$ \\
\hline \multirow[t]{2}{*}{ Importance to participant } & Not important & $46(9.9)$ \\
\hline & Important & $48(10.3)$ \\
\hline \multirow[t]{3}{*}{ Caregivers } & Mother & $429(92.5)$ \\
\hline & Father is working & $323(69.6)$ \\
\hline & Mother is working & $273(58.8)$ \\
\hline \multirow[t]{2}{*}{ Family economic status } & Difficult & $68(14.7)$ \\
\hline & Comfortable & $378(81.5)$ \\
\hline \multirow[t]{3}{*}{ Language spoken at home } & French & $136(29.3)$ \\
\hline & English & $109(23.5)$ \\
\hline & Other & $216(46.9)$ \\
\hline \multirow[t]{3}{*}{ Language spoken with friends } & French & $290(62.5)$ \\
\hline & English & $109(23.5)$ \\
\hline & Other & $62(13.4)$ \\
\hline \multirow[t]{3}{*}{ Speaks French } & Not at all or a little bit & $33(7.1)$ \\
\hline & Rather good & $170(36.6)$ \\
\hline & Very well & $254(54.7)$ \\
\hline \multirow[t]{3}{*}{ Speaks English } & Not at all or a little bit & $174(37.5)$ \\
\hline & Rather good & $125(26.9)$ \\
\hline & Very well & $150(32.3)$ \\
\hline \multirow[t]{5}{*}{ Talks to in need } & Parent(s) & $374(80.6)$ \\
\hline & Sibling(s) & $263(56.7)$ \\
\hline & Extended family & $138(29.7)$ \\
\hline & Friend(s) & $327(70.5)$ \\
\hline & No one & $5(1.1)$ \\
\hline Consulted a mental health & & $106(22.8)$ \\
\hline
\end{tabular}

The largest proportion of students (46.6\%) was comprised of second generation immigrants. This was closely followed by first generation immigrants (42.7\%), with 16\% born in Asia, 7.8\% in the Caribbean, 7.5\% in the Middle East, 6.9\% in Central and Latin American, and 4.5\% in sub-Saharan Africa, while a small percentage of students were born to 
mixed couples $(6.0 \%)$, and $4.3 \%$ were of Canadian origin. In spite of this, only $6.7 \%$ of the sample identified themselves as Canadian. Near half the sample (49.6\%) self-identified as "Other" and 20.9\% reported not knowing what their identity was.

Reasons for immigration were economical (11.4\%) and political $(8.4 \%)$ reasons, better education (6.5\%), and discrimination in the country of origin (3.0\%). Thirty-three percent $(33.0 \%)$ of youth did not know why their families had immigrated. About $13 \%$ of respondents reported witnessing violence or that their families had endured persecution in their countries of origin.

Almost all (92.5\%) of these youth reported being cared for by their mothers, and $65.3 \%$ reported being cared for by their fathers. Interestingly, $68.5 \%$ reported having also some other source of care (such as extended family or siblings). Two thirds of the adolescents (61.6\%) lived in normal two-parent family settings, and a third (34.5\%) lived with a single parent. Only $5(1.1 \%)$ students were cared for by neither parent. Almost $70 \%$ of the fathers and $60 \%$ of the mothers of the students were employed. The youth lived in households with an average of five members. Some spoke French $(29.3 \%)$ or English $(23.5 \%)$ at home, but most (46.9\%) reported speaking another language. The majority evaluated their family economic status as being comfortable $(81.5 \%)$.

Most of the students (62.5\%) spoke French with their peers, with half of them (54.7) reporting fluency in French and a third (32.3\%) reporting the same in English.

Except for a handful (5 participants), the teens reported having confidents; mostly parents (80.6\%) and friends (70.5\%), then siblings (56.7\%) and extended family (29.7\%).

Regarding the use of mental health services, a fifth of the adolescents $(22.8 \%)$ reported having consulted a mental health professional.

The youth had an average of 11.51 (4.92) emotional and behavioral symptoms (SDQ total score) as reported by them, and 9.56 (6.38) as evaluated by their teachers (Table 2). The score on the SDQ Impact Supplement, which assesses the overall impact of emotional and behavioral symptoms, was 0.57 (1.18) when completed by the adolescents and 1.52 (1.74) as scored by teachers. Around a fifth of the students were at or above the cutoff of 16 for the SDQ total score when measured by self $(n=92,19.8 \%)$ or teacher $(n=83,17.9 \%)$. With regards to impairment, one quarter of the students $(n=124,26.7 \%)$ scored themselves at or above the cutoff of 1 in the SDQ Impact Supplement, and half of them were evaluated as such by their teachers $(\mathrm{n}=253,54.5 \%)$. Inter-informant (youth-teacher) agreement was $\mathrm{r}=.25(\mathrm{p}<.001)$ for the SDQ total score and $r=.14(p=.003)$ for the SDQ Impact Supplement.

Table 2. Clinical Characteristics

\begin{tabular}{llll}
\hline Instrument & \multicolumn{3}{l}{ N (\%) or Mean (SD) } \\
\hline Strengths and Difficulties Questionnaire (SDQ) & Self Report & Teacher's Report \\
\hline Emotional and behavioral symptoms & Emotional symptoms & $2.60(2.08)$ & $2.37(2.43)$ \\
& Conduct problems & $2.42(1.71)$ & $1.40(2.01)$ \\
& Hyperactivity/inattention & $4.13(2.14)$ & $3.68(2.60)$ \\
& Peer relationship problems & $2.36(1.80)$ & $2.11(2.16)$ \\
& Prosocial behavior & $7.60(1.95)$ & $7.29(2.53)$ \\
& Total score & $11.51(4.92)$ & $9.56(6.38)$ \\
Total Impact & Caseness & $92(19.8)$ & $83(17.9)$ \\
& Score & $0.57(1.18)$ & $1.52(1.74)$ \\
Relations with Peers (AFI) & Caseness & $124(26.7)$ & $253(54.5)$ \\
Classroom Environment (CE) & & $91.28(11.21)$ & \\
School Grades & & & \\
& & $84.48(19.04)$ & \\
& & & \\
& & $61.46(12.17)$ & \\
\hline
\end{tabular}

The score for the youth' relationships with their peers as measured by AFI was 91.28 (11.21). The score for the classroom environment on the WIHIC was 84.48 (19.04).

The students' average grades in French and Mathematics were 61.46 (12.17) and 58.67 (16.01), respectively. 
Both self- and teacher-reported total symptoms were significantly negatively correlated to French (self: $\mathrm{r}=-.13, \mathrm{p}=.015$, teacher: $\mathrm{r}=-.18, \mathrm{p}=.001$ ) and mathematics (self: $\mathrm{r}=-.15, \mathrm{p}=.006$, teacher: $\mathrm{r}=-.17, \mathrm{p}=.002$ ) grades. Bivariate (Pearson) correlation analysis revealed a significant negative correlation $(r=-.10, p=.028)$ between self SDQ total score and age. Teacher SDQ total score was significantly lower for girls than for boys $(t=2.64, p=.009)$. Although there were no significant differences in emotional or behavioral symptoms or in academic performance between first and second generation youth, self SDQ total score was significantly higher among youth who had witnessed violence or endured persecution in their countries of origin $(\mathrm{t}=1.97, \mathrm{p}=.050)$. Not being cared for by the mother significantly increased total symptoms self-reported by youth $(t=2.18, \mathrm{p}=.029)$. Self SDQ total score was significantly higher for students' reporting a lower socioeconomic status $(t=2.73, \mathrm{p}=.007)$. Youth peer relationships as measured by the AFI were significantly negatively correlated with the SDQ total score as reported by the student $(r=-23, p<.001)$ but not by the teacher. The WIHIC classroom climate score was not only associated with the self SDQ total score $(r=-.10, p=.033)$ but also with the teacher-reported SDQ score $(\mathrm{r}=-.14, \mathrm{p}=.004)$. The WIHIC score was significantly correlated with both French $(\mathrm{r}=.17, \mathrm{p}=.002)$ and mathematics $(\mathrm{r}=.12, \mathrm{p}=.028)$ grades. This was not the case for the AFI.

Table 3 illustrates the model explaining self-reported SDQ total symptoms, which acted as the dependent variable, while age, gender, witnessing violence or persecution in the country of origin, being cared for by mother, family economic status, classroom environment, peer relationships, French and mathematics grades, as well as the interaction between classroom environment and French grades and between classroom environment and mathematics grades were independent variables. The overall model was significant: adjusted $r^{2}=0.15 ; F(\mathrm{df} 11,17)=3.88, P<.001$. Having a mother caregiver and positive relationships with peers made significant contributions while the rest of the variables did not.

Table 3. Multiple Linear Regression Model for Self SDQ Total Difficulties

\begin{tabular}{|c|c|c|c|c|c|c|c|}
\hline \multirow[b]{3}{*}{ Independent variables } & \multicolumn{7}{|c|}{ Dependent variable: Self SDQ total difficulties } \\
\hline & \multirow[b]{2}{*}{ B } & \multirow[b]{2}{*}{ SE B } & \multirow[b]{2}{*}{ Beta } & \multirow[b]{2}{*}{$T$} & \multirow[b]{2}{*}{$\boldsymbol{P}$} & \multicolumn{2}{|c|}{$95 \%$ CI for B } \\
\hline & & & & & & $\begin{array}{l}\text { Lower } \\
\text { bound }\end{array}$ & $\begin{array}{l}\text { Upper } \\
\text { bound }\end{array}$ \\
\hline Constant & 42.634 & 12.650 & & 3.370 & .001 & 17.664 & 67.605 \\
\hline Age & -.527 & .275 & -.135 & -1.919 & .057 & -1.069 & .015 \\
\hline Gender & .374 & .706 & .038 & .530 & .597 & -1.020 & 1.769 \\
\hline $\begin{array}{l}\text { Witnessed violence or } \\
\text { was persecuted }\end{array}$ & 1.005 & .824 & .087 & 1.219 & .225 & -.622 & 2.631 \\
\hline Caregiver: mother & -8.092 & 2.327 & -.245 & -3.478 & .001 & -12.685 & -3.499 \\
\hline Economic status & -.819 & .957 & -.060 & -.856 & .393 & -2.707 & 1.069 \\
\hline AFI & -.101 & 034 & -.221 & -2.980 & .003 & -.169 & -.034 \\
\hline Classroom environment & -.016 & .130 & -.048 & -.119 & .905 & -.273 & .242 \\
\hline French & .097 & .158 & .245 & .612 & .541 & -.215 & .408 \\
\hline Mathematics & -.151 & .122 & -.510 & -1.237 & 218 & -.391 & .090 \\
\hline CE*French & -.002 & .002 & -.467 & -.837 & .404 & -.005 & .002 \\
\hline $\mathrm{CE}^{*}$ Mathematics & .001 & .001 & .416 & .826 & .410 & -.002 & .004 \\
\hline
\end{tabular}

Adjusted $\mathrm{r}^{2}=0.15$

SDQ, Stengths and Difficulties Questionnaire

Table 4 demonstrates the results of multiple linear regression analysis with teacher-reported SDQ total symptoms as the dependent variable, and age, gender, family economic status, French and mathematics grades and the interaction between classroom environment with French and classroom environment with mathematics grades as the independent variables. The overall model was significant with adjusted $r^{2}=0.11, F(\mathrm{df} 11,17)=3.03, P=.001$. Only age was significantly associated with teacher SDQ total symptoms score. 
Table 4. Multiple Linear Regression Model for Teacher SDQ Total Difficulties

\begin{tabular}{|c|c|c|c|c|c|c|c|}
\hline \multirow[b]{3}{*}{ Independent variables } & \multicolumn{7}{|c|}{ Dependent variable: Teacher SDQ total difficulties } \\
\hline & \multirow[b]{2}{*}{ B } & \multirow[b]{2}{*}{ SE B } & \multirow[b]{2}{*}{ Beta } & \multirow[b]{2}{*}{$T$} & \multirow[b]{2}{*}{$\boldsymbol{P}$} & \multicolumn{2}{|c|}{$95 \%$ CI for B } \\
\hline & & & & & & $\begin{array}{l}\text { Lower } \\
\text { bound }\end{array}$ & $\begin{array}{l}\text { Upper } \\
\text { bound }\end{array}$ \\
\hline Constant & 51.607 & 16.612 & & 3.107 & .002 & 18.817 & 84.397 \\
\hline Age & -.879 & .358 & -.176 & -2.454 & .015 & -1.585 & -.172 \\
\hline Gender & -1.568 & .923 & -.126 & -1.699 & .091 & -3.389 & .254 \\
\hline $\begin{array}{l}\text { Witnessed violence or } \\
\text { was persecuted }\end{array}$ & .010 & 1.077 & .001 & .010 & .992 & -2.115 & 2.136 \\
\hline Caregiver: mother & -2.095 & 3.043 & -.050 & -.689 & 492 & -8.101 & 3.911 \\
\hline Economic status & -1.778 & 1.251 & -.102 & -1.421 & .157 & -4.248 & .692 \\
\hline AFI & -.006 & .044 & -.010 & -.135 & .893 & -.093 & .081 \\
\hline $\begin{array}{l}\text { Classroom environment } \\
\text { (CE) }\end{array}$ & -.182 & .172 & -.437 & -1.058 & .291 & -.520 & .157 \\
\hline French & -.308 & .206 & -.611 & -1.494 & 137 & -.716 & .099 \\
\hline Mathematics & -.134 & .160 & -.354 & -.840 & .402 & -.449 & .181 \\
\hline CE*French & .003 & .002 & .613 & 1.070 & .286 & -.002 & .007 \\
\hline CE*Mathematics & .001 & .002 & .177 & .341 & .733 & -.003 & .004 \\
\hline
\end{tabular}

Adjusted $r^{2}=0.11$

SDQ, Strengths and Difficulties Questionnaire

\section{Discussion}

As expected, the sociodemographic profile of the youth in the special classes in Montreal multiethnic high schools reveals that they serve almost exclusively immigrant communities, with $43 \%$ first generation youth and $47 \%$ second generation, most of whom do not self-identify as Canadian. Interestingly, the mental health and academic achievement of first and second generation adolescents in these special education settings are similar, while in general population samples, both in the US and in Canada, first generation students tend to do better than their second generation peers (Rousseau, Hassan, Measham, \& Lashley, 2008).

Bivariate analysis reveals that youth premigratory history, family environment (mother as caretaker and family socioeconomic situation), youth peer relationships, and class environment are all associated with youth emotional or behavioral difficulties. Class environment is significantly associated with youth academic performance in French and mathematics. This is in line with the well-established relation between classroom context (which includes student-teacher relationship quality) and adolescent academic achievement (Greene, Miller, Crowson, Duke, \& Akey, 2004; Stipek \& Miles, 2008). Dotterer and Lowe (2011) have, however, shown that this association may be less important for youth with previous academic difficulties, as is the case in this study. With respect to immigrant children, Han (2008) suggests that even if some immigrant groups may respond more to school level factors than others, overall school resources and school-based relationships are key factors in immigrant children's academic engagement (Suarez-Orozco et al., 2009). It is not possible to know how the balance between those factors that may have opposite effects influenced the observed association in this sample. In a longitudinal study examining the impact of psychological distress at age 13-14 on the educational achievement at the end of compulsory education, Rothon and collaborators (2009) conclude that emotional and behavioral difficulties (as measured by the SDQ) do influence achievement, and they emphasize the need for more support of emotionally distressed youth within school. The very high level of teacher-reported youth impairment, which coincides with the research team's qualitative observations of teachers' feeling of burden, indicates that teachers may feel too overwhelmed to provide this support.

The multiple regression models integrating the interaction between classroom environment and academic performance, although significant overall, highlight only a few significant correlates: mother as caretaker and peer relationships for the self-report, and only age for the teacher report. Maurizi and collaborators (2013a) have shown that positive relationships with the mother and with some peers moderate the association between depressive symptoms and academic achievement. In this study, although these variables appear to be important correlates of youth emotional and behavioral difficulties, the amount of overall variance explained remains low, probably due to the absence of key variables like family conflict and cohesion, which, in other high school research explained most of the variance observed (Rousseau et al., 2008). 
This study has a number of limitations which are partly inherent to an in-school survey with youth presenting important academic delays. Because the questionnaire had to be short and simple, the number of instruments included was small, and important variables, like the premigratory context or the family environment, were documented only through a few questions. School belonging was not directly documented; it might have complemented the classroom environment measure by better describing the connection between the youth and their school.

This is however the first study describing the correlates of emotional and behavioral difficulties in special classes servicing immigrant communities in Canada. The results emphasize the need to address the role of the school environment in supporting immigrant adolescents identified as having difficulties by the school system. The salience of peer relationships and classroom environment for adolescent emotional and behavioral difficulties suggests that schools need to promote positive school-based relationships to improve both immigrant adolescents' mental health and academic achievement and thus buffer some of the stigma which may be associated with the experience of being in a special class.

\section{Acknowledgements}

This study was supported by a grant from the Canadian Institutes of Health Research Grant No. : 111059.

\section{References}

Aldridge, J. M., Fraser, B. J., Fisher, D. L., \& Wood, D. (2002). Assessing students' perceptions of outcomes-based, technology-rich learning environments. Paper presented at the American Educational Research Association, New Orleans.

Barowsky, E. I., \& McIntyre, T. (2010). Migration and relocation trauma of young refugees and asylum seekers: Awareness as prelude to effective intervention. Childhood Education, 86(3), 161-168. http://dx.doi.org/10.1080/00094056.2010.10523138

Bauer, A. M., Keefe, C. H., \& Shea, T. M. (2001). Students with learning and emotional/behavioural disorders. New Jersey: Merrill/Prentice-Hall.

Benner, G. J., Nelson, J. R., \& Epstein, M. H. (2002). Language skills of children with EBD: A literature review. Journal of Emotional and Behavioral Disorders, 10(1), 43-59. http://dx.doi.org/10.1177/106342660201000105

Bibeau, G., Chan-Yip, A., Lock, M., Rousseau, C., \& Sterlin, C. (1992). La santé mentale et ses visages: Vers un québec pluriethnique au quotidien. Montréal: Gaëtan Morin, 289 pages.

Coutinho, M. J., Oswald, D. P., Best, A. M., \& Forness, S. R. (2002). Gender and sociodemographic factors and the disproportionate identification of culturally and linguistically diverse students with emotional disturbance. Behavioral Disorders, 27(2), 109-125.

Dotterer, A. M., \& Lowe, K. (2011). Classroom context, school engagement, and academic achievement in early adolescence. Journal of Youth and Adolescence, 40(12), 1649-1660. http://dx.doi.org/10.1007/s10964-011-9647-5

Glick, J. E., \& White, M. J. (2003). The academic trajectories of immigrant youths: Analysis within and across cohorts. Demography, 40(4), 759-783. http://dx.doi.org/10.1353/dem.2003.0034

Goodman, R. (2001). Psychometric properties of the Strengths and Difficulties Questionnaire (SDQ). Journal of the American Academy of Child \& Adolescent Psychiatry, 40, 1337-1345. http://dx.doi.org/10.1097/00004583-200111000-00015

Greene, B. A., Miller, R. B., Crowson, H. M., Duke, B. L., \& Akey, K. L. (2004). Predicting high school students' cognitive engagement and achievement: Contributions of classroom perceptions and motivation. Contemporary Educational Psychology, 29(4), 462-482. http://dx.doi.org/10.1016/j.cedpsych.2004.01.006

Han, W.-J. (2008). The academic trajectories of children of immigrants and their school environments. Developmental Psychology, 44(6), 1572. http://dx.doi.org/10.1037/a0013886

Kanouté, F., Vatz Laaroussi, M., Rachédi, L., \& Tchimou Doffouchi, M. (2008). Familles et réussite scolaire d'élèves immigrants du secondaire. Revue des Sciences de l'Éducation, 34(2), 265-289. http://dx.doi.org/10.7202/019681ar

Kia-Keating, M., \& Ellis, B. H. (2007). Belonging and connection to school in resettlement : Young refugees, school belonging, and psychosocial adjustment. Clinical Child Psychology and Psychiatry, 12(1), 29-43. http://dx.doi.org/10.1177/1359104507071052 
Lambros, K. N., Ward, S. L., Bocian, K. M., MacMillan, D. L., \& Gresham, F. M. (1998). Behavioural profiles of children at risk for emotional and behavioural disorders: Implications for assessment and classification. Focus on Exceptional Children, 30(5), 1-15.

Maurizi, L. K., Ceballo, R., Epstein-Ngo, Q., \& Cortina, K. S. (2013a). Does neighborhood belonging matter? Examining school and neighborhood belonging as protective factors for Latino adolescents. American Journal of Orthopsychiatry, 83(2-3), 323-334. http://doi.org/10.1111/ajop.12017

Maurizi, L. K., Grogan-Kaylor, A., Granillo, M. T., \& Delva, J. (2013b). The role of social relationships in the association between adolescents' depressive symptoms and academic achievement. Children and Youth Services Review, 35(4), 618-625. http://dx.doi.org/10.1016/j.childyouth.2013.01.006

Rock, E. E., Fessler, M. A., \& Church, R. P. (1997). The concomitance of learning disabilities and emotional/behavioral disorders: A conceptual model. Journal of Learning Disabilities, 30(3), 245-263. http://dx.doi.org/10.1177/002221949703000302

Rothon, C., Head, J., Clark, C., Klineberg, E., Cattell, V., \& Stansfeld, S. (2009). The impact of psychological distress on the educational achievement of adolescents at the end of compulsory education. Social Psychiatry and Psychiatric Epidemiology, 44(5), 421-427. http://dx.doi.org/10.1007/s00127-008-0452-8

Rousseau, C., Drapeau, A., \& Corin, E. (1996). School performance and emotional problems in refugee children. American Journal of Orthopsychiatry, 66(2), 239-251. http://doi.org/10.1037/h0080175

Rousseau, C., Drapeau, A., \& Rahimi, S. (2003). The complexity of trauma response: A 4-year follow-up of adolescent Cambodian refugees. Child Abuse \& Neglect, 27(11), 1277-1290. http://doi.org/10.1016/j.chiabu.2003.07.001

Rousseau, C., Hassan, G., Measham, T., \& Lashley, M. (2008). Prevalence and correlates of conduct disorder and problem behavior in Caribbean and Filipino immigrant adolescents. European Child \& Adolescent Psychiatry, 17(5), 264-273. http://doi.org/10.1007/s00787-007-0640-1

Rubenstein, J. L., Heeren, T., Housman, D., Rubin, C., \& Stechler, G. (1989). Suicidal behavior in "normal" adolescents: Risk and protective factors. American Journal of Orthopsychiatry, 59(1), 59-71. http://dx.doi.org/10.1111/j.1939-0025.1989.tb01635.x

Rumbaut, R., \& Portes, A. (2001). Ethnicities: Children of immigrants in America. New York: University of California Press. Russell Sage Foundation.

Stipek, D., \& Miles, S. (2008). Effects of aggression on achievement: Does conflict with the teacher make it worse? Child Development, 79(6), 1721-1735. http://dx.doi.org/10.1111/j.1467-8624.2008.01221.x

Suarez-Orozco, C., Pimentel, A., \& Martin, M. (2009). The significance of relationships: Academic engagement and achievement among newcomer immigrant youth. The Teachers College Record, 111(3), 712-749.

Van Hook, J., \& Stamper Balistreri, K. (2002). Diversity and change in the institutional context of immigrant adaptation: California schools 1985-2000. Demography, 39(4), 639-654. http://dx.doi.org/10.1353/dem.2002.0042 